\title{
Shared thoughts on Ivan Soskov (1954-2013)
}

\author{
Stela Nikolova \\ Sofia University "St. Kliment Ohridski" \\ Faculty of Mathematics and Informatics \\ 5, James Bourchier Blvd., 1164 Sofia, Bulgaria \\ stenik@fmi.uni-sofia.bg \\ http://www.fmi.uni-sofia.bg/fmi/logic/nikolova/
}

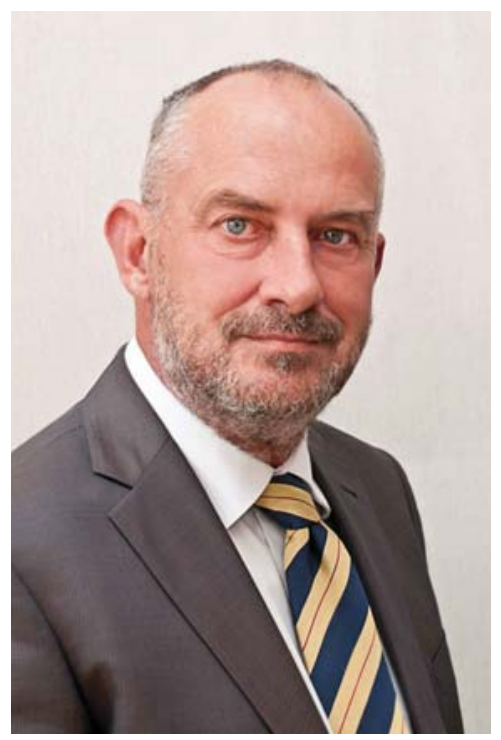

Ivan Soskov (1954-2013)

"There is only one thing permanent in this life, and that is change"

Just after midnight on the first day of orthodox Easter, Ivan Soskov passed away as a result of an allergic shock to a bee sting. I was a witness to roughly half of Ivan's 59 years and am slowly getting used to his absence while thinking about Ivan's path in life and sense of purpose and mission.

Once, when he was about thirty years old, had left behind the careless days of his youth, and had recently defended his doctoral dissertation, he had discussed the issue of a purpose in life with friends and wondered whether he would be able to live his life in a way that would earn him the naming of a street.

In the spring of 2013, Ivan and I were talking about his roots and Ivan was in a talkative mood. He had just submitted his (unfortunately, last) paper and told me that he is resigning from thinking about maths. Both his maternal and his paternal families come from Southern Bulgaria. When I ask him whether they were war refugees, he answers: "No, they weren't, they had always lived there, simply natives." His maternal grandfather, Georgi Rafailov (cf. Figure 1), was a notary's son from Nova Zagora. "It is interesting that my great-grandfather managed to support my grandfather as a student in Paris with a modest salary of a small town notary. Would that be possible today?" 


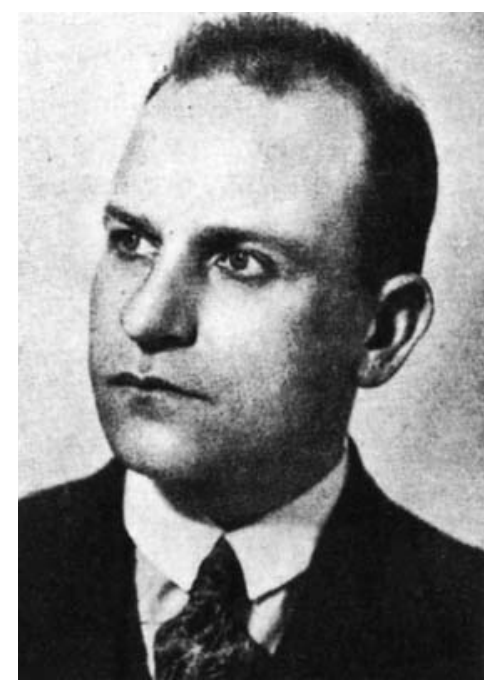

Figure 1. Dr. Georgi Rafailov, Ivan Soskov's maternal grandfather.

Ivan's great-grandfather's trust in his son was not misplaced and Georgi Rafailov met his father's expectations completely: he graduated with honours from the Sorbonne and later defended a doctorate at the same university. Georgi had just turned thirty when he met Elena while walking on the Champs Élysées. A couple of words were enough to find out that they were compatriots, from the same town even living in close neighbourhoods. Elena was young, beautiful, and intelligent. She was fresh out of Robert College of Istanbul and was rewarded by her father with the trip to Paris for the brilliant graduation. In addition to her college degree, la Belle Hélène had won the crown in the 1927 graduates beauty pageant. In the following year, Ivan's mother Rose Marie was born in Paris.

At that time, it was a matter of honour for young Bulgarians educated abroad, that they return home to bring the knowledge acquired abroad as well as the spirit and culture of Europe back to their home country. After defending his doctoral thesis, Dr. Georgi Rafailov established a home for his family in his hometown and started his career as a lawyer. I asked Ivan: "Had your grandfather remained in Nova Zagora, would you have been his colleague now?" Ivan emerged from his thoughts and answered: "I could have been."

Surprisingly, Ivan Soskov, who seemed to many of us a person born to be a mathematician, had dreamt about studying law. Maybe this was because studying law had been his mother's unfulfilled dream; or because there had been three lawyers in his maternal family? However, very early on, Ivan had realized that his future would not involve studying law. Ivan's grandfather, Georgi Rafailov rapidly gained the respect of the Bulgarians and was elected as a member of parliament in 1941; as a consequence, the family moved to Sofia. These were uneasy times: the Second World War had just started, and Bulgaria was Germany's ally. Bulgarians are particularly proud of the fact that they resisted the deportation of the Bulgarian jews to the death camps. Ivan's grandfather, who was chairing the legislative committee of the Bulgarian parliament at the time, was amongst the 43 members of the parliament who signed the Declaration against the Deportation of the Jews from Bulgaria. Famously, the Bulgarian jews were saved; but in the aftermath of the Second World War, those involved in the declaration were less fortunate: they were killed as alleged Nazi collaborators, buried in a trench, their families were interned, and their property confiscated. Ivan's dreams of studying law were deeply affected by this. However, Ivan had forgiven the unfair treatment of his family: he never complained about it, and after the fall of the Iron Curtain, he did not benefit from his status of someone who had been prosecuted by communism and he did not join any party.

Ivan was born on 23rd September 1954 in Stara Zagora, his father's hometown. His paternal grandfather Dr. Ivan Soskov was a respected physician in the city; Ivan's father, Dr. Nikolay Soskov was a pulmonologist and worked in mountain sanatoria during the early years of his career. This is why Ivan spent his childhood with his grandparents in Stara Zagora. Ivan used to recall their "beautiful house with a gorgeous winter garden" and his German grandmother Else, who raised him. Ivan's grandfather had met Else during his university studies in Germany and returned to his 

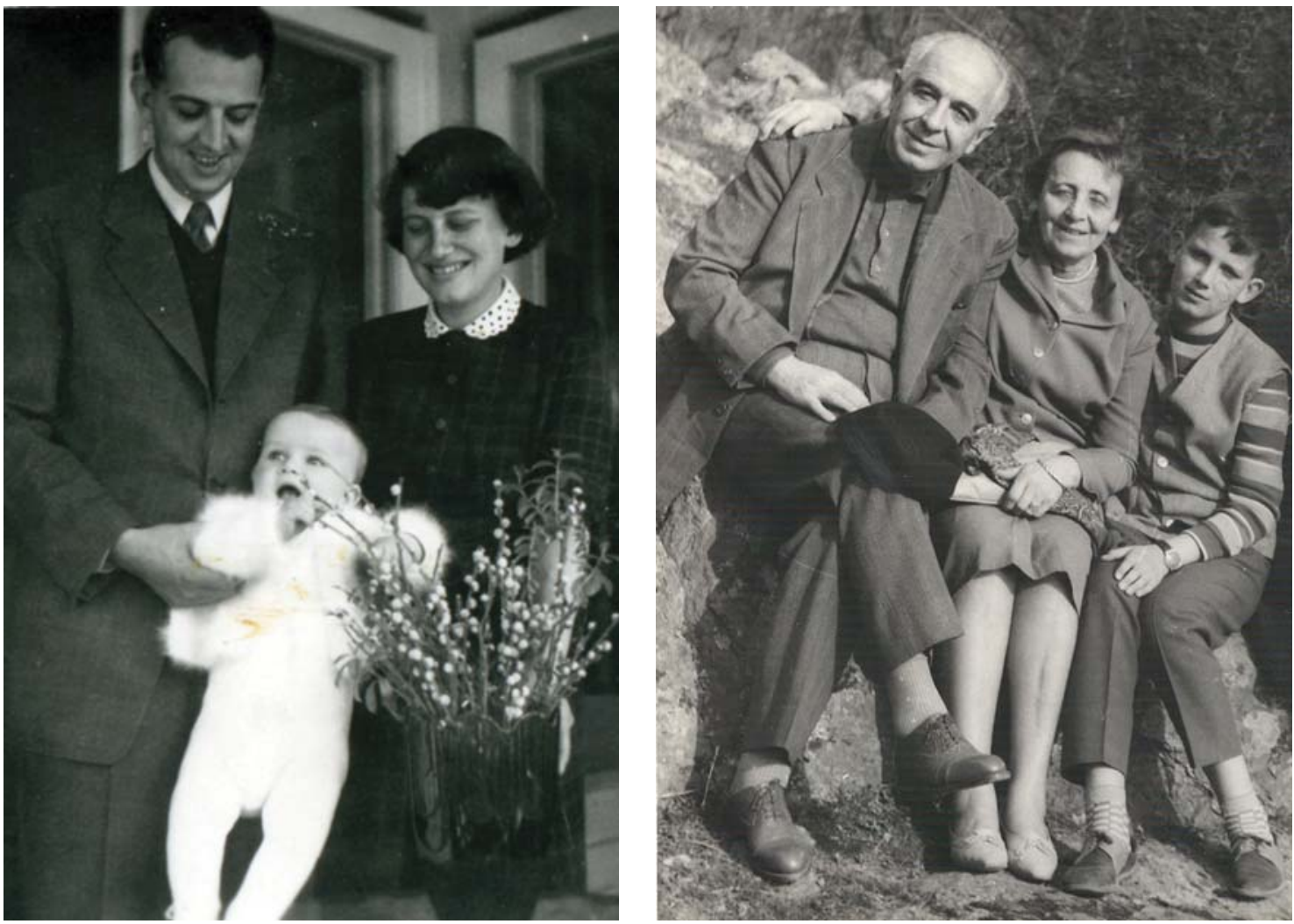

Figure 2. Left: Ivan as a baby with his parents. Right: Ivan with his grandparents Else and Ivan.

hometown with her after graduation. Bulgaria became Else's second homeland (although she was interned in a work camp by the communists after the Second World War as a German; fortunately, this episode of Ivan's family history had a happy ending). Ivan's early teenage years were his hardest: in the course of three years he lost his grandmothers Elena and Else and his mother. Possibly, the grief was one of the reasons why on the day of his high school entrance exam, he refused to get up and go to the exam. In frustration, Ivan's father slapped him in the face with immediate effect. In later years, Ivan's father often joked that Ivan's career in mathematics started with a slap in the face. By a remarkable coincidence, that day, at that entrance exam for the National High School of Mathematics, Ivan met Dimiter Skordev, his future mentor and teacher in computability theory.

Dr. Kiril Kalev was one of Ivan's closest friends and recollects Ivan's period as a high school student:

We were brought together by our school in the heart of Sofia. At dusk, after the last bell ring we would head with the rest of the gang to an attic where until the early hours we would discuss, argue, play music and sing about our experiences, dreams and hopes. Ivan was the one, who with his subtle sense of humor and intellect, made every friendly gathering unique. We often talked in rhyme. His quiet and poetic passion was known only to a few of us - the closest friends, because it came from the heart and would often not make it through the socialist censorship.

The late 1960s and early 1970s were a dark period for our free spirit. In the Cold War whirl the music of Jimi Hendrix, Beatles, Doors, Rolling Stones, etc, of all titans of English music pop-culture were unwelcome and banned in Bulgaria. During our house parties and gatherings outside Sofia we used to disguise as hippies, to try to recreate somehow subconsciously but very realistically a mini free society, wherein pop music and poetry, the free communication, jokes, and prank were not in accordance with the communist gyves and restrictions. That was a world of our own, which filled us and compensated what the dictatorship had deprived us of, a world that made us really happy. These reminiscences are still living nowadays. 

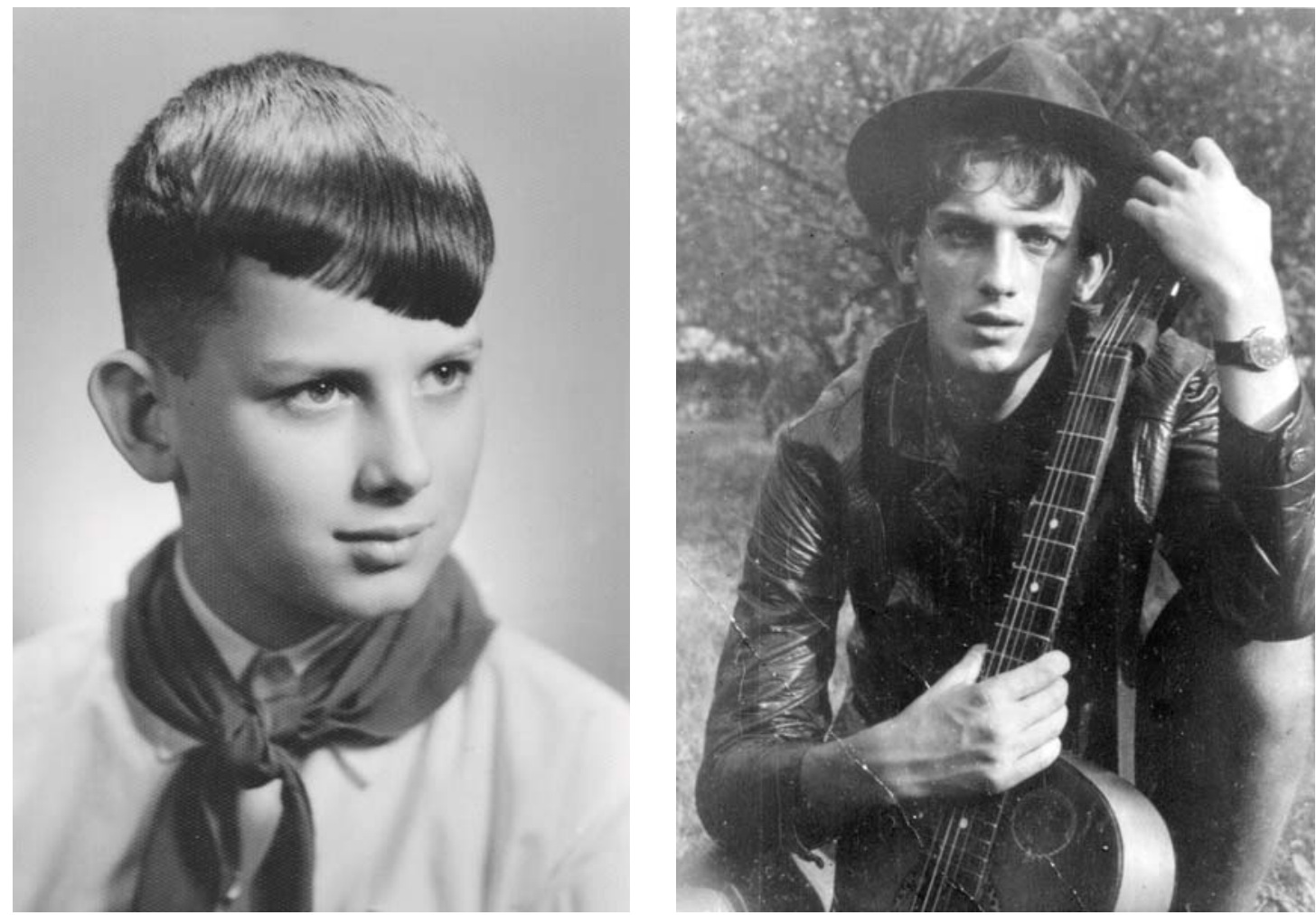

Figure 3. Left: Ivan as a boy scout. Right: Ivan at Rebarkovo near Sofia, 1971

In his play Bustle, the Bulgarian writer Yordan Radichkov says: "The way you get into the bustle is not important. The way you get out of it is important." Ivan got into mathematics on the advice of his father, but he immediately developed a mature and professional attitude, as is reported by Denka Kutzarova who studied with Ivan for four years at the university:

In the summer after our first university year, a group of students gathered at a mountain camp to train for a math Olympiad for universities from the Balkan countries. It was a surprise for me to learn that Ivan returned to Sofia after only a couple of days. I asked: "But why? True, we have no Olympiad experience, but we came here mainly for the training, didn't we?" - "I don't need it. Olympiads are one thing, research is something else. Olympiad problems, no matter how hard, have already been solved by someone. You can play a mind game with the people who gave you the problem, guessing how they think and what level of difficulty you may expect. In research you face something entirely new, nobody knows how to solve it, or even if it has a solution. I don't deny Olympiad skills are useful for it; still research is a different game, the real game, much more exiting! I've decided in which mathematical area I want to specialize and I talked to the leading professor in mathematical logic. He shall be my advisor."

The professor Ivan was talking about was Dimiter Skordev (cf. Figure 4). As an undergraduate student, Ivan took almost all courses from the Master's programme in Mathematical Logic, including Skordev's well-known course on Computability; and as Ivan had announced, Skordev did become his advisor, both for his Master's and doctoral theses. Skordev recalls this period as follows:

In the academic year 1978/1979, as a supervisor of Ivan Soskov's Master's Thesis, I had the chance to be a witness of his first research steps in the Computability Theory. My role was rather easy thanks to Ivan's great ingenuity and strong intuition. Several years later, in 1983, Ivan Soskov defended his remarkable PhD dissertation on computability in partial algebraic systems. Although I was indicated as his supervisor again, actually no help of mine was needed 


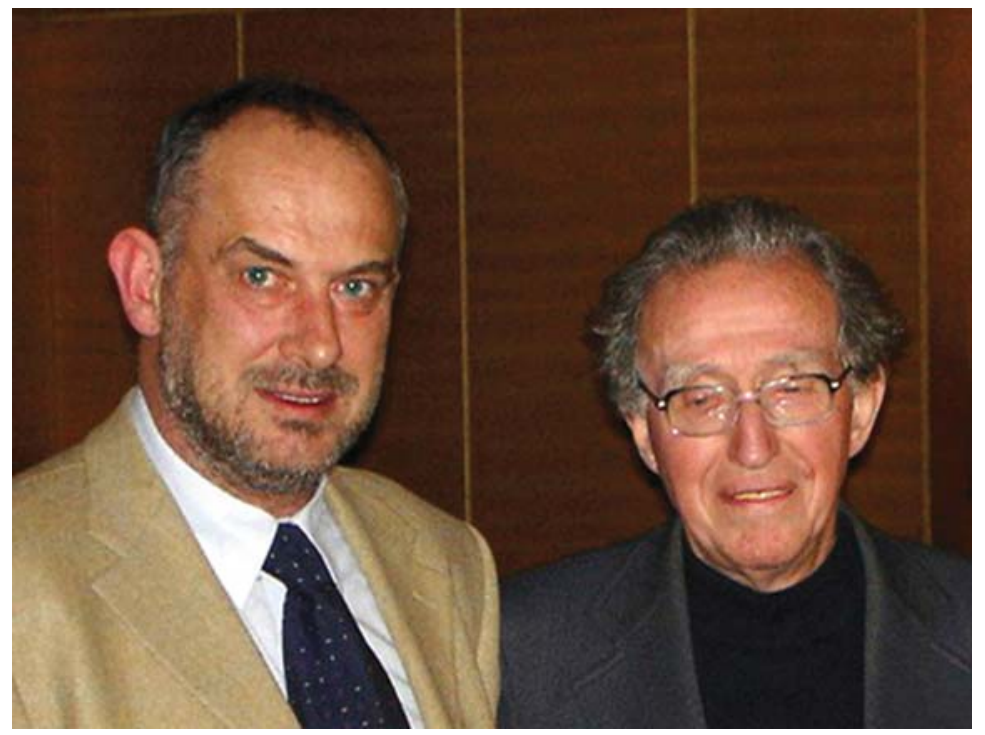

Figure 4. With Dimiter Skordev in Sofia, 2005

at all in the creation of this dissertation. Everything in it, including also the choice of its subject and the form of the presentation, was a deed of Ivan only.

Our further communication with Ivan enriched me with new ideas and a new perspective on things. From him I've also learned a lot about basic skills in using computers. When about a quarter of a century ago computers began to enter our work, Ivan Soskov was the one who made sure that we, his colleagues from the Department acquired the necessary skills. During the past decades I have always seen him as a benevolent and well-meaning colleague with true perspective on values in mathematics, who I deeply respected and who I thought of as a friend. Ivan Soskov left us in the prime of his creativity, full of ideas and plans for the field of science, teaching and administration. His absence creates a huge void in my life as a mathematician. His outstanding contributions however remain, and I hope that his numerous former students will be able to continue his work.

The year 1986 saw the first of a series of international conferences, organized by our department. The conference was attended by a number of prominent scientists from all over the world. Ivan was particularly happy to meet Yiannis Moschovakis (cf. Figure 5) in person: Moschovakis's notions of prime and search computability had been central to Ivan's doctoral dissteration entitled "Computability in algebraic systems". Moschovakis recalls their first encounter:

I met Ivan Soskov in 1986, at an International Conference on Mathematical Logic in Druzhba, near Varna. It was an important and very successful meeting, the first (I believe) in Bulgaria which included among its many distinguished speakers several from "the West" as we said then, and it was conducted almost entirely in English. The organizers were Dimiter Skordev and Petio Petkov, and I suppose I owed my invitation to the fact that I knew Skordev quite well from his visiting UCLA some time earlier.

Almost thirty years later, I still have very vivid memories of the Druzhba meeting, some from the talks and the place, but most from the young Bulgarian logicians I met there. They were a lively group, with close professional and personal connections among them.

I remember especially a dinner in the garden of a farm house that (I believe) had been rented for the meeting by Soskov and Lyubomir Ivanov with their families; several of the logic graduate students and Post Docs in Sofia were there, including (I think) Solomon Passy, Angel Dichev and Tinko Tinchev. The guest of honor was Albert Dragalin, another first-rate logician who died too young, and his lively and humorous conversation dominated the evening. But I was mostly taken by the young Bulgarians, their easy interactions and their intelligent and inquisitive discussion of every 

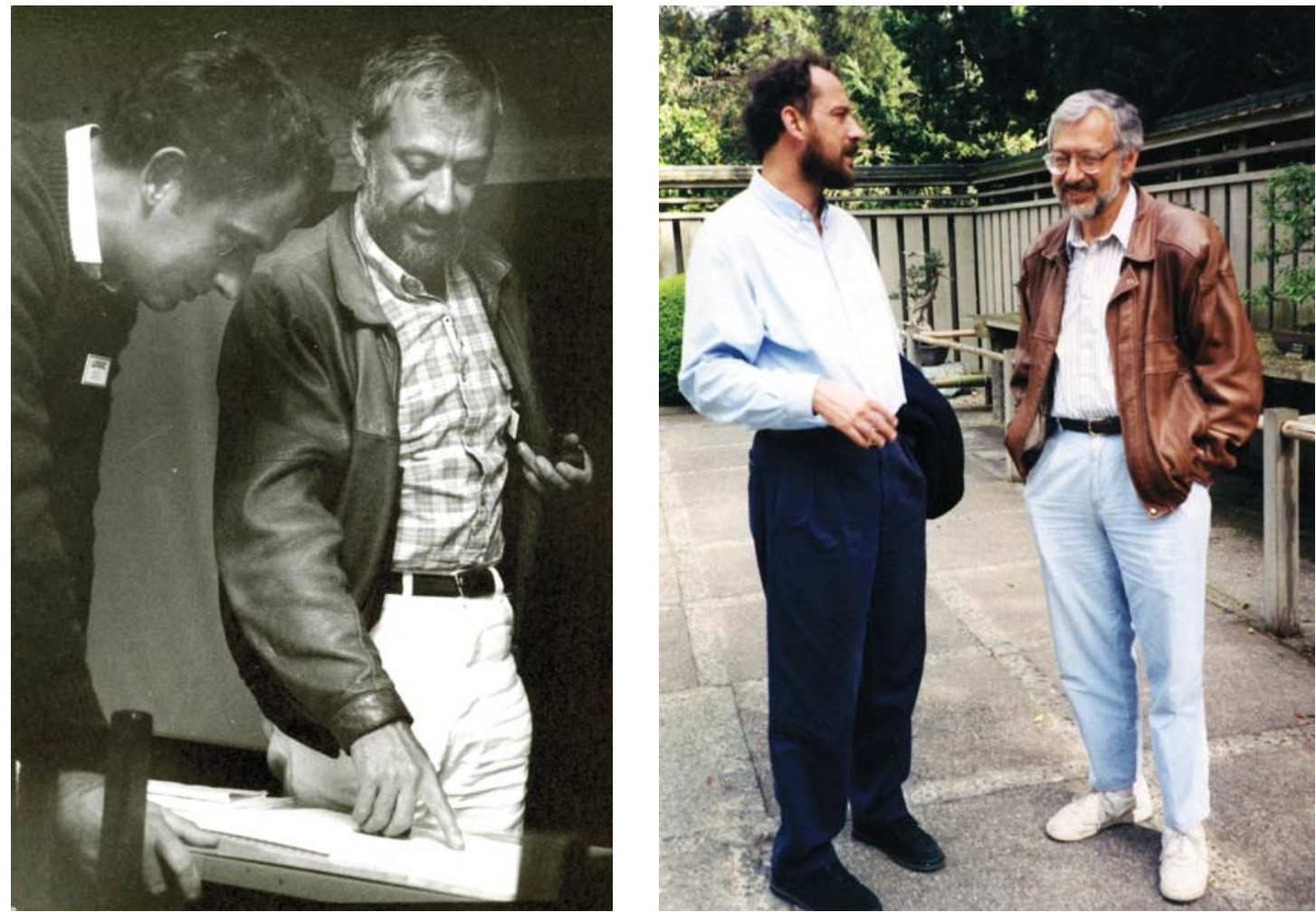

Figure 5. Left: With Yiannis Moschovakis at the International Conference in Druzhba near Varna, 1986. Right: With Yiannis Moschovakis at Huntington Park, California, 1992.

aspect of logic that came up. I remember thinking that if this sort of active logic group could be built in Sofia, then why not in Athens; and some years later we tried to imitate them, with some success.

I met with Soskov many times after that, including the two years (1991-1993) that he spent at UCLA, his visit to Athens in the Fall Term of 1999-2000, where he taught a terrific course on "Automata and applications" that I audited, and several conferences in Bulgaria. We became close friends, and I learned a great deal from him. But I know that I will always remember him most and best from that warm, late summer evening in Druzhba, with the vivid mixture of logic, youthful enthusiasm and Balkan garden smells.

Mathematics was central to Ivan's life, as is witnessed by the following report of his daughter, Mariya Soskova (cf. Figure 6):

My earliest mathematical memory is of my father, in the morning, coffee in his hand, sparkle in his eyes, talking excitedly about forcing. It sounded so mysterious and powerful... I decided then, I will do whatever it takes to find out what it means. This is how it always was, he would never push you to do something, rather he would make it seem so interesting and meaningful, that you would be drawn to it. This is how I learned how to ride a bike and swim and ski, and how I got into computability. Later on, we would talk about math, research and the meaning of it all for many hours. He thought of mathematics as a way of uncovering deep and important ideas, he thought that people in this field share an invisible bond in some ways stronger than our bonds to people we see every day. Math was never work for him, it was his purpose. The reward was his own satisfaction and a nice novel, or an interesting movie, or a long dinner with music in the background and pleasant conversation. It was a wonderful experience to be able to share all of that with him. 


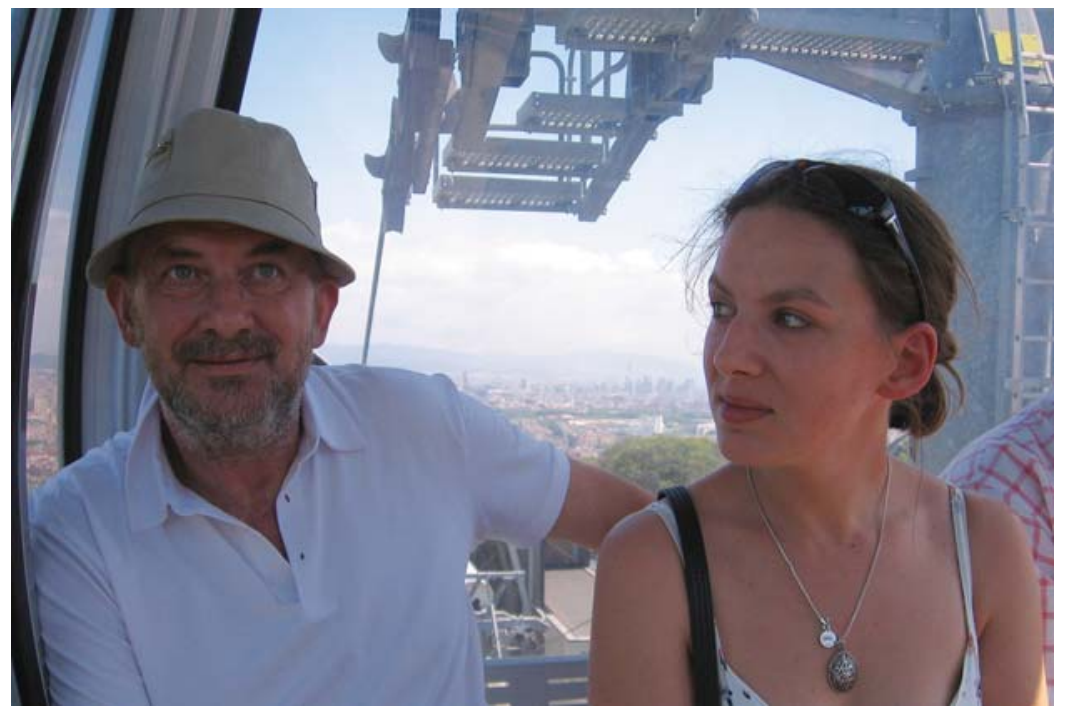

Figure 6. Ivan with his daughter Mariya, Barcelona, 2011

This impression is corroborated by Mariya's mother, Alexandra Soskova:

I will never forget how his eyes would light up when he was talking about mathematics. And this was everywhere: in the office, at the seminar, at the lectures, at home, at lunch or while taking a walk in the park. We would listen and try to understand the ideas, while they were getting more and more interesting, like magic. Working with him was an adventure. He had a very good sense of the quality of an idea. When he said "Yes, this is worth it", I was always convinced that it was indeed; not only about mathematics, about life in general as well. He was very generous with his time and made your mathematical experience seem like part of something grand. I will always be grateful for these shared moments.

Ivan Soskov spent his entire career at the Faculty of Mathematics and Informatics at Sofia University, climbing the academic ladder from being a programmer at the computing laboratory in 1983 to being the Dean of the Faculty. For many years he has played a major role in the management of Sofia University and the research administration of Bulgaria. His work was greatly appreciated by his colleagues, as the following quote from Nadya Zlateva, the Vice-Dean of the Faculty of Mathematics and Informatics at Sofia University shows:

Professor Soskov was not only an outstanding man and a brilliant mathematician but he was a charismatic leader. As the Dean of our Faculty during the last 6 years Prof. Soskov contributed to the rise of the authority of the Faculty. He made huge efforts for increasing the level of education of students, for accelerating the career development of lecturers and for improving the working conditions for all. He led the department with honesty and integrity, and enjoyed the respect of all colleagues and students.

Although Ivan did not get involved in politics, he was a politician and visionary at heart, tolerant and diplomatic, but determined when defending his ideas and goals. When he was a student, he studied together with Dr. Solomon Passy, who later become the Foreign Minister of Bulgaria. Passy recalls:

Ivan was an unforgettable friend, an ingenious mathematician and extremely diplomatic colleague. He would solve the problems that others would not even phrase. He was a master at turning an awkward silence into a lively discussion with a constructive way out. And he was always equally effective: in the auditorium, at a workshop, at an international conference or among friends! 


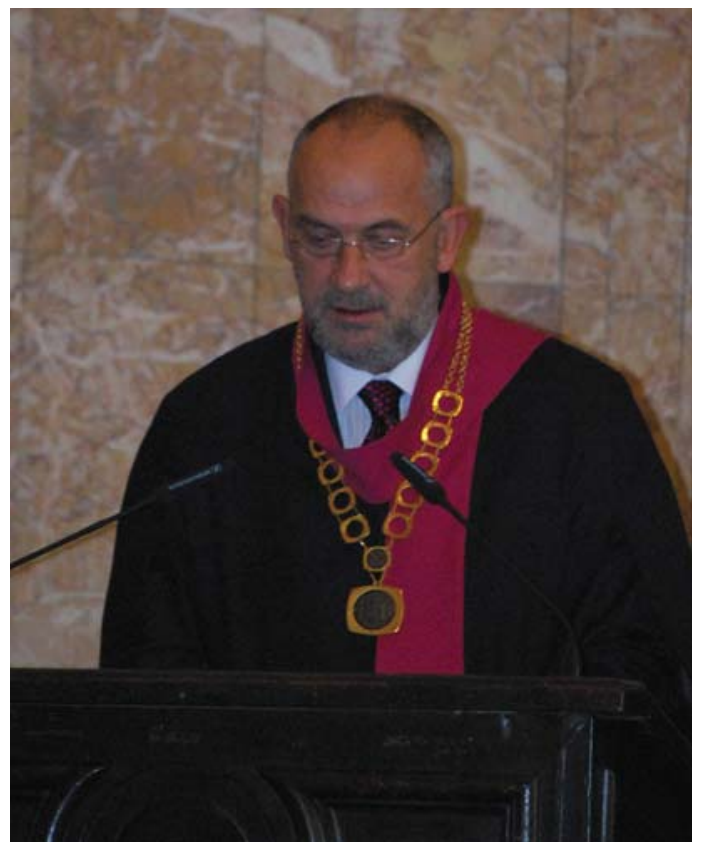

Figure 7. Ivan Soskov at a graduation ceremony in the Rectorate of Sofia University, 2010

Ivan Soskov supervised a large number of Master's and doctoral students and wrote about forty research papers. He left us "The school Soskov", in which he built in his own mathematical spirit. Soskov enjoyed the respect of his colleagues abroad. As an illustration, we give quotes from three of these colleagues that were close to Ivan:

I came across the work of Professor Ivan Soskov in the late 90s, when I first read his paper on jump inversion in the enumeration degrees. Since then, I always admired him, although I never met him until recently. Ivan has been one of those mathematicians who introduce new ideas and new directions of study and research. Thus it is not surprising that under his leadership, the University of Sofia has seen the rise of such a fine and successful group of logic.

When I met Ivan in 2007, I was able to appreciate his great human qualities: His broad culture, his friendly and generous manners, his smiling eyes. We have lost an excellent mathematician, and personally I have lost a dear friend. (Andrea Sorbi)

I always appreciated the deep insight Ivan had into the field of computable structure theory. It allowed him to do some great mathematics. A couple of my favorite things he did that come to mind are: the work on Intrinsic Pi-1-1 relations, the work on jumps of structures, and the work on omega-jump-inversions. I admire his work quite a bit. And also his personality. He'll be missed. (Antonio Montalban)

Ivan was a man with a mission, it seemed to his friends and family. And the mission was to look after you. He was on your side. It was like the eyes of the Mona Lisa, Ivan's belief in you followed, whatever. He knew the world was a dangerous (and wonderful) place. Walking the earth with Ivan was a very real and rewarding experience. Because he cared about the real things... (S. Barry Cooper, cf. Figure 8)

Teaching was not just a part of his job commitment for Ivan: he loved to teach, respected his students and enjoyed their respect as well. One of his recent students, Ivan Georgiev, reports about Ivan Soskov's teaching:

Professor Soskov was an incredible man and teacher. Without any doubt, my journey in logic (and that of many other colleagues as well) began with the curiosity he managed to provoke during his courses on theoretical computability. Professor Soskov sparked our love and commitment to science and this spark along with the bright memories of him will always shine over our way ahead. 


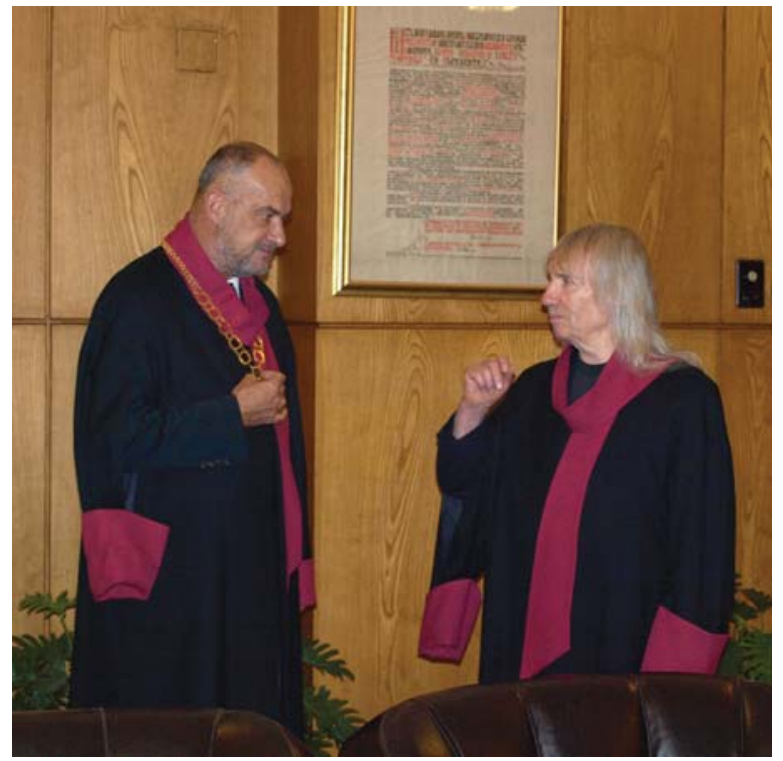

Figure 8. With S. Barry Cooper before ceremony awarding Cooper the honorary doctorate of Sofia University, 2011

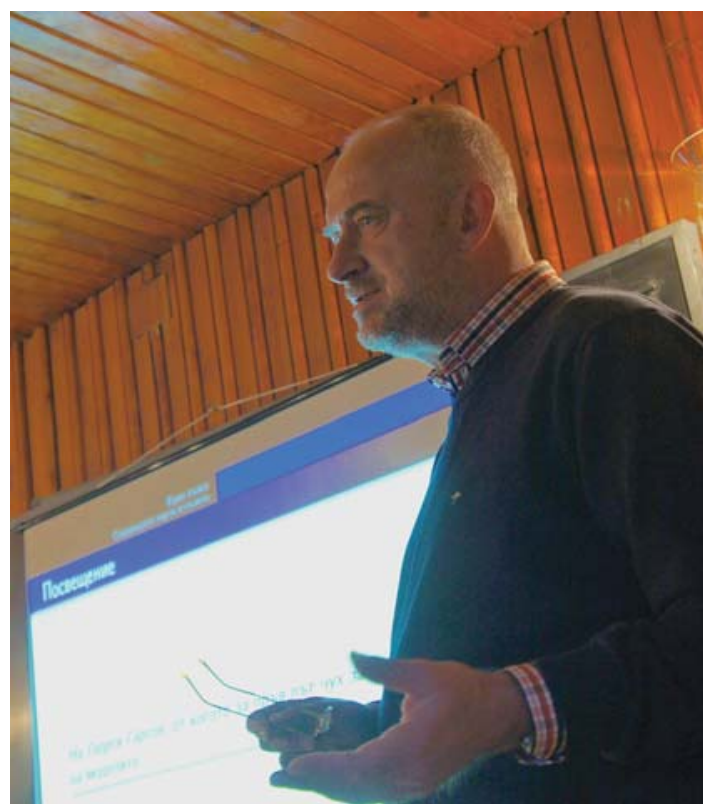

Figure 9. Celebration of the 40th anniversary of the Department of Logic, Gyolechitza, November 2012

Ivan's aunt Ekaterina Rafailova claimed that Ivan inherited his rhetorical skills and his brilliant sense of humour from his grandfather, the politician. There are two stories that illustrate this.

The first story happened in late 2002. During an award ceremony for Dimiter Skordev in the Rectorate of Sofia University, Ivan and I were sitting in the back of the lecture hall. Yordan Mitev, the Dean of the Faculty at that time, uttered a few introductory words and then immediately gave the floor to Ivan. Ivan quietly mumbled something and I asked: "Didn't you know about this?". As he stood up and headed for the podium, he answered: "No." Then 
he delivered a fulminant speech. When I asked him later how he had managed to do that, he replied modestly: "Fortunately, we were sitting in the back, so I had some time to prepare while I was walking to the front of the lecture hall."

My second story happened earlier this year in spring. Very early in the morning, the committee for an entrance examination met in the Rectorate of Sofia University. All members of the committee were tired, except for Ivan. The entrance examination starts with an official opening in a huge lecture hall; I happened to be a few minutes late for this opening, and as I was approaching the lecture hall, I heard that the entire hall burst into laughter. When I entered the hall, I saw the Dean of the Faculty, Ivan Soskov, dressed in an elegant suit and with dignified bearing, who is charming the future students with his words about the beauty of mathematics. These young people will never have the chance to take a course with Ivan, and they will never hear the words that Ivan used to start all of his courses: "Mathematics is like love: you have to experience it, having someone else tell you about it is not enough. But I'll try." Similarly, I believe, Ivan had to be experienced, and having someone else tell you about Ivan is not enough. I tried.

\section{Acknowledgements}

I would like to thank cordially all colleagues, friends, and students of Ivan that kindly accepted my invitation to share their thoughts and memories. I am grateful as well to Ekaterina Rafailova and Emilia Soskova who informed me about the roots of their family and patiently answered my questions. Thanks are also due to Ivanka Ivanova and Mariya Soskova for proofreading and corrections. 